Article

\title{
Impact of Indigenous Non-Saccharomyces Yeasts Isolated from Madeira Island Vineyards on the Formation of Ethyl Carbamate in the Aging of Fortified Wines
}

\author{
João Micael Leça ${ }^{1,2}$, Vanda Pereira ${ }^{2,3, * \mathbb{D}}$, Andreia Miranda ${ }^{1,2,4}$, José Luis Vilchez ${ }^{5}$, Manuel Malfeito-Ferreira ${ }^{6} \mathbb{D}$ \\ and José Carlos Marques ${ }^{1,2,3}$
}

1 Faculty of Exact Sciences and Engineering, Campus da Penteada, University of Madeira, 9020-105 Funchal, Portugal; jmleca@staff.uma.pt (J.M.L.); afmiranda@uma.pt (A.M.); marques@uma.pt (J.C.M.)

2 Institute for Nanostructures, Nanomodelling and Nanofabrication (i3N), University of Aveiro, 3810-193 Aveiro, Portugal

3 ISOPlexis-Sustainable Agriculture and Food Technology Center, Campus da Penteada, University of Madeira, 9020-105 Funchal, Portugal

4 Henriques \& Henriques-Vinhos S.A., Avenida da Autonomia, 9300-138 Câmara de Lobos, Portugal

5 Research Group of Analytical Chemistry and Life Sciences, Department of Analytical Chemistry, University of Granada, 18071 Granada, Spain; jvilchez@ugr.es

6 Linking Landscape, Environment, Agriculture and Food Research Center (LEAF), Instituto Superior de Agronomia, University of Lisbon, Tapada da Ajuda, 1349-017 Lisboa, Portugal; mmalfeito@isa.ulisboa.pt

Citation: Leça, J.M.; Pereira, V.; Miranda, A.; Vilchez, J.L.; Malfeito-Ferreira, M.; Marques, J.C. Impact of Indigenous Non-Saccharomyces Yeasts Isolated from Madeira Island Vineyards on the Formation of Ethyl Carbamate in the Aging of Fortified Wines. Processes 2021, 9, 799. https:// doi.org/10.3390/pr9050799

Academic Editor: Anet Režek Jambrak

Received: 22 March 2021

Accepted: 26 April 2021

Published: 1 May 2021

Publisher's Note: MDPI stays neutral with regard to jurisdictional claims in published maps and institutional affiliations.

Copyright: (C) 2021 by the authors Licensee MDPI, Basel, Switzerland. This article is an open access article distributed under the terms and conditions of the Creative Commons Attribution (CC BY) license (https:/ / creativecommons.org/licenses/by/ $4.0 /)$.
* Correspondence: vpereira@uma.pt

Abstract: The impact of selected non-Saccharomyces yeasts on the occurrence of ethyl carbamate (EC) was evaluated. Hanseniaspora uvarum, Starmerella bacillaris, Pichia terricola, Pichia fermentans and Pichia kluyveri isolated from Madeira Island vineyards were inoculated in Tinta Negra musts. Urea, citrulline (Cit) and arginine (Arg) were quantified when the density of musts attained the levels to obtain sweet (1052 $\pm 5 \mathrm{~g} / \mathrm{L})$ and dry (1022 $\pm 4 \mathrm{~g} / \mathrm{L})$ Madeira wines. The urea concentration varied between 1.3 and $5.3 \mathrm{mg} / \mathrm{L}$, Cit from 10.6 to $15.1 \mathrm{mg} / \mathrm{L}$ and Arg between 687 and $959 \mathrm{mg} / \mathrm{L}$. P. terricola and S. bacillaris generated lower levels of urea $(<2.5 \mathrm{mg} / \mathrm{L}), \mathrm{Cit}(<11.0 \mathrm{mg} / \mathrm{L})$ and $\operatorname{Arg}(<845.6 \mathrm{mg} / \mathrm{L})$. The five resulting fortified wines, individually fermented by the selected non-Saccharomyces yeast, were exposed to laboratory-accelerated aging at $70{ }^{\circ} \mathrm{C}$ for 1 month. From the studied yeasts, P. terricola and S. bacillaris revealed a lower potential to form EC $(<100 \mu \mathrm{g} / \mathrm{L})$; therefore, both yeasts can be a useful tool for its mitigation in wines.

Keywords: non-Saccharomyces yeasts; ethyl carbamate; urea; citrulline; arginine; fortified wine

\section{Introduction}

The use of selected indigenous starters from the complex biota of specific environments is a new trend in the wine sector [1]. Studies on indigenous yeasts adapted to specific grape varieties and regions have grown in number in recent years, not only with the purpose of evaluating biodiversity but also for selecting new indigenous strains associated with "terroir" in order to produce different types and styles of wine [2,3]. Particularly, there is a growing interest in non-Saccharomyces yeasts given that selected strains can have a positive impact on wine quality. These yeasts can be inoculated singularly or included in a mix of yeast starters to compensate for their poor fermenting capacities. Non-Saccharomyces yeasts are also known to inhibit undesirable microorganisms [4]. Yeast metabolism is also responsible for producing several flavor compounds that can ensure wine quality as well as other compounds that can be related with off-flavors or even food contaminants, which can compromise its commercialization.

Ethyl carbamate (EC) was classified as a probable carcinogen (group 2A) by the International Agency for Research on Cancer in 2010 [5]. Canadian authorities advanced 
with the first legislation in 1985 [6] and recently reviewed the maximum levels set for EC in certain alcoholic beverages: table wine, $30 \mu \mathrm{g} / \mathrm{kg}$; fortified wine, $100 \mu \mathrm{g} / \mathrm{kg}$; distilled spirits, $150 \mu \mathrm{g} / \mathrm{kg}$; sake, $200 \mu \mathrm{g} / \mathrm{kg}$; and fruit brandies and liqueurs, $400 \mu \mathrm{g} / \mathrm{kg}$ [7]. Other countries have also established their own legislation, but the imposition of an EC concentration limit in alcoholic beverages is not consensual $[5,8]$. EC is mainly formed after wine fermentation by the reaction of carbamoyl compounds with ethanol [6]. Urea and citrulline (Cit) are considered the most relevant precursors of EC [6,7], and both are mainly formed from intracellular metabolism of Arg. Urea is mainly generated by yeasts during the early and middle stages of fermentation, and Cit is generated through Arg anabolism by Saccharomyces cerevisiae or even by lactic acid bacteria (LAB) [8,9]. Thus, Arg, commonly the most abundant amino acid in grape juice, has been considered a preponderant metabolite of EC formation [10].

External factors such as the storage temperature and the maturation time can have a marked influence on the final concentration of EC in wine [11-13]. The mitigation of $\mathrm{EC}$ in wine has been focused on the urea reduction in the medium, namely by using selected commercial yeast strains with low urea excretion [11]. Different yeast strains have been studied for their urea excretion and uptake during fermentation [14], being verified that distinct strains lead to different concentrations of urea in the extracellular medium. Additionally, it has been concluded that different must compositions also influence urea metabolism during fermentation. An increase in Arg and amino acids in general promotes the accumulation of urea in the grape must [15]. Moreover, the aeration of must during fermentation at specific moments can also influence the final concentration of urea in the medium. It is therefore recognized that yeasts with high urea production have a high affinity to convert Arg into urea and a low ability to metabolize urea. Genetic factors can influence the amount of urea that is released and taken up by yeast cells [11]. The procedures recommended to minimize EC content involve the reduction in storage time and temperature and the use of acidic ureases and genetic engineering tools focused on the yeast genes responsible for urea metabolism $[8,16]$. Despite the fact that these strategies can be viable solutions for EC mitigation in specific beverages, the impact of their application on the typical characteristics and quality of fortified wines is still not known.

Fortified wines have unique organoleptic characteristics, generally resulting from their specific winemaking processes and aging. These wines have a high alcohol content $(15-22 \%)$ due to the addition of a neutral grape spirit or vinous alcohol during the winemaking process, called alcoholic fortification. Different procedures are used in the production of the world's best-known fortified wines, namely Sherry, Port, and Madeira, resulting in a wide range of wine styles with different sugar levels, from extra dry to sweet $(>96 \mathrm{~g} / \mathrm{L})[17,18]$. The distinctive features of Madeira wine are influenced by basalt soil that is rich in organic matter, the proximity to the sea and the moderate climatic conditions with hot humid summers and mild winters [19]. The Tinta Negra red grape variety represents between 80 and $85 \%$ of the total production on Madeira Island (Portugal) and can be used in the production of all Madeira wine styles: sweet, medium sweet, dry and medium dry $[17,19,20]$. The fermentation process of Madeira wine is frequently conducted using grape native yeasts and its extension depends on the wine style to be produced, with fermentation being halted when the desired sweetness is attained by raising the alcohol content, usually up to $17-17.5 \%(\mathrm{v} / \mathrm{v})$, with the addition of vinous alcohol. Thus, the timing of interrupting alcoholic fermentation in drier wines happens at a later stage, while in sweeter wines, this happens at an earlier stage. In Madeira wine appellation, the "extra dry" label is attributed to fortified wines with less than $49 \mathrm{~g} / \mathrm{L}$ of residual sugars, even if alcoholic fermentation was not complete $(<2 \mathrm{~g} / \mathrm{L})$. After vinification, young wines can follow one of the two traditional aging processes before bottling: estufagem (a thermal processing usually followed by the majority) or canteiro (usually used for selected wines). Detailed information about Madeira winemaking is reported elsewhere [17].

As far as we are aware, there is no studies about the impact of non-Saccharomyces yeasts on the occurrence of EC and its precursors in wines referenced in the literature. 
Therefore, the aim of this study was to assess the impact of indigenous non-Saccharomyces isolates from Hanseniaspora uvarum, Starmerella bacillaris, Pichia terricola, Pichia fermentans and Pichia kluyveri on the formation of EC and its precursors when individually inoculated in Tinta Negra musts for producing fortified wine.

\section{Materials and Methods}

2.1. Microorganisms and Samples

\subsubsection{Yeast Isolation and Identification}

Tinta Negra Vitis vinifera L. (red) represents the most cultivated grape variety used to produce Madeira wine. The indigenous non-Saccharomyces yeast strains used in the current study were isolated from musts of this cultivar from Estreito de Câmara de Lobos, Madeira Island (Portugal). This was achieved by using a glucose-yeast-peptone (GYP) medium (20 g/L glucose from Sharlau (Barcelona, Spain) and $5 \mathrm{~g} / \mathrm{L}$ peptone, $5 \mathrm{~g} / \mathrm{L}$ yeast extract and $20 \mathrm{~g} / \mathrm{L}$ Nutrient Agar from Himedia (Einhausen, Germany)). The isolates were directly collected from a single colony. The polymerase chain reaction-restriction fragment length polymorphism (PCR-RFLP) was carried out using an ITS1 primer $\left(5^{\prime}-\right.$ TCCGTAGGTGAACCTGCGG-3') and an ITS4 primer (5'-TCCTCCGCTTATTAGATATGC$3^{\prime}$ ) from STABVida (Lisbon, Portugal). The DNA isolation and polymerase chain reaction (PCR) conditions were based on the literature [21]. Amplified DNAs were digested with NZYTaq II DNA Polymerase from NZYTech, Lda-genes and enzymes (Lisbon, Portugal). The DNA products and their restriction fragments were separated on $1.5 \%$ agarose gel from Cleaver Scientific (London, UK with $1 \times$ TAE buffer. The species were identified based on the internal transcribed spacer (ITS) fragment sequence (STABVida, Lisbon, Portugal) and a blast analysis for the sequences obtained.

\subsubsection{Inoculation and Wine Production}

The yeast strains used for inoculation in the present study, H. uvarum, S. bacillaris, P. terricola, P. fermentans and P. kluyveri, were isolated from Tinta Negra grape musts produced in the south of Madeira Island (municipality of Câmara de Lobos), with a pH of 3.07 and a density of $1075 \mathrm{~g} / \mathrm{L}$, equivalent to about $196 \mathrm{~g} / \mathrm{L}$ of dissolved sugar according to the VinoLab and Vinocalc online calculator tools.

A batch of Tinta Negra grape must was manually prepared at laboratory scale (in duplicate) in amber glasses $(10 \times 3 \mathrm{~L})$, with headspace for carbon dioxide release, and individually inoculated with the isolates of the different non-Saccharomyces yeasts. To do so, bunches were first picked, and then, berries were manually separated from stems and crushed. The must was boiled at $105^{\circ} \mathrm{C}$ for $5 \mathrm{~min}$ in 3-liter glass jars to deactivate the typical microorganisms found in grape musts. The procedure for yeast inoculation was based on the literature [22]. Briefly, yeast strains were cultivated in GYP broth at $25^{\circ} \mathrm{C}$ for $24 \mathrm{~h}$ up to $10^{8} \mathrm{CFU} / \mathrm{mL}$ (determined using Thoma cell counting chamber method) and inoculated to give an initial count of $10^{6} \mathrm{CFU} / \mathrm{mL}$. The fermentations followed the typical Madeira winemaking process, under a controlled temperature $\left(20 \pm 3^{\circ} \mathrm{C}\right)$, and samples were collected when the density reached the values at which the alcoholic fortification is generally performed to obtain sweet (about $1052 \mathrm{~g} / \mathrm{L}$, equivalent to $135 \mathrm{~g} / \mathrm{L}$ of dissolved sugar) and dry Madeira wines (about $1022 \mathrm{~g} / \mathrm{L}$, equivalent to $57 \mathrm{~g} / \mathrm{L}$ of dissolved sugar) (Table 1). During the experiment, the density was measured using a pycnometer. The experiments conducted with H. uvarum, S. bacillaris and P. terricola yielded sweet and dry wine samples. P. fermentans and P. kluyveri showed a poor fermenting performance and only sweet wines were sampled. 
Table 1. Final density of wines fermented with the different non-Saccharomyces yeast strains isolated from Madeira wine vineyards.

\begin{tabular}{lcc}
\hline \multicolumn{1}{c}{ Yeast } & Sweet Wines (g/L) & Dry Wines (g/L) \\
\hline Hanseniaspora uvarum & $1054 \pm 3$ & $1020 \pm 5$ \\
Starmerella bacillari & $1059 \pm 1$ & $1021 \pm 1$ \\
Pichia terricola & $1052 \pm 1$ & $1026 \pm 1$ \\
Pichia kluyveri & $1051 \pm 1$ & - \\
Pichia terricola & $1045 \pm 1$ & - \\
\hline
\end{tabular}

\subsubsection{Alcoholic Fortification and Wine Accelerated Aging}

The fermentations were arrested by adding vinous alcohol $(95 \%(\mathrm{v} / \mathrm{v})$ of ethanol) up to $17 \%(\mathrm{v} / \mathrm{v})$ of alcohol. The alcohol content was previously determined by FTIR and UV-Vis through the Bacchus 3 Multispec analyzer (calibrated with routine measurements based on the OIV standard procedure [23]) in order to define the volume of neutral grape spirit needed for the adjustment. After fortification, the wines were clarified and stabilized through bentonite clays and albuminocol gelatins (Proenol S.A., Portugal) while resting for 1 month at room temperature. Five different wines were obtained in duplicate, namely 3 dry wines (H. uvarum, S. bacillaris and P. terricola) and 2 sweet wines (P. fermentans and P. kluyveri). Each resulting wine (in duplicate) was aged at laboratory scale in a 500-milliliter glass flask at $70^{\circ} \mathrm{C}$ for 1 month in an ED115 laboratory heating chamber (Binder, Tuttlingen, Germany), mimicking the long-term aging of Madeira wine [9,24,25].

\subsection{Determination of Ethyl Carbamate, Urea, Citrulline and Arginine}

Before analysis, all samples were previously filtered through Chromafil PTFE 0.2micrometer syringe filters (Macherey-Nagel, Düren, Germany), while eluents were filtered through PTFE 0.2-micrometer pore size membranes (Pall Corporation, Ann Arbor, MI, USA). Ultra-pure water (type 1), obtained from a Simplicity UV apparatus from Millipore (Milford, MA, USA), was used for the preparation of aqueous mobile phases.

An in-house method was followed for the quantitative determination of EC formation, consisting of a miniaturized liquid-liquid extraction followed by reversed-phase liquid chromatography with detection by electrospray tandem mass spectrometry (RP-HPLCMS/MS), as previously described in [26]. The extraction of samples $(15 \mathrm{~mL})$ was vortex assisted using $8 \mathrm{~mL}$ of ethyl acetate, followed by $\mathrm{N}_{2}$ evaporation. The residue was then redissolved up to a final volume of $1 \mathrm{~mL}$ in aqueous mobile phase before the analysis. The calibration was within the range of $1-250 \mu \mathrm{g} / \mathrm{L}$, with $\mathrm{R}^{2}=0.999$, a limit of quantification (LOQ) of $0.5 \mu \mathrm{g} / \mathrm{L}$ and a recovery rate between 96 and $116 \%$. The repeatability and reproducibility never exceeded $9 \%$ of relative standard deviation (RSD).

Urea, Arg and Cit were analyzed by chemical derivatization in a liquid chromatography system from Waters Alliance (Milford, MA, USA) with an auto-injector (Waters 2695 separations module) coupled with a Multi $\lambda$ Fluorescence detector (Waters 2475). Data acquisition and processing were performed using the Empower Pro software. The following chemicals were used for these analyses (purity grade $>97 \%$ ): urea, Arg and Cit standards were obtained from Sigma-Aldrich (St. Louis, MO, USA); 9-xanthydrol, ortho-phthalaldehyde (OPA) and 2-mercaptoethanol (MCE) were obtained from Acros Organics (Geel, Belgium); 1-propanol from Lab-Scan (Gliwice, Poland); acetonitrile HPLC gradient grade from Fisher Scientific (Leicestershire, UK); hydrochloric acid from Riedel-de Haën (Seelze, Germany); methanol (UPLC grade), formic acid, absolute ethanol, tartaric acid potassium hydroxide, potassium di-hydrogen phosphate, iodoacetic acid (IDA) and tetrahydrofuran from Panreac (Barcelona, Spain); and boric acid was purchased from Merck Co. (Darmstadt, Germany). All samples were prepared in duplicate and derivatized in triplicate.

Quantification of urea was based on a previously published method [27] and significant changes were introduced. 9-Xanthydrol was used for the derivatization into the HPLC injection loop, followed by reversed phase separation and fluorescence de- 
tection (RP-HPLC-FLD). The urea derivatization reaction was set as follows: $10 \mu \mathrm{L}$ of sample/standards, $10 \mu \mathrm{L}$ of $4 \mathrm{~g} / \mathrm{L}$ 9-xanthydrol solution (in 1-propanol), $8 \mu \mathrm{L}$ of $1.5 \mathrm{M}$ hydrochloric acid and $10 \mu \mathrm{L}$ of acetonitrile; and kept in the loop for $15 \mathrm{~min}$ and loaded into a Kinetex C18 column, $150 \times 4.6 \mathrm{~mm}, 5 \mu \mathrm{m}, 100 \AA$, from Phenomenex (Torrance, CA, USA), thermostated at $30{ }^{\circ} \mathrm{C}$. Gradient mode was used at $1 \mathrm{~mL} / \mathrm{min}$, with $1 \%$ formic acid (solution A) and methanol (solution B), as follows: solution A at $60 \%$ for 1 min was changed to $41 \%$ for $8.60 \mathrm{~min}$, set to $0 \%$ for the following $2.4 \mathrm{~min}$, maintained for $1 \mathrm{~min}$ and, finally, increased to $60 \%$ for $1 \mathrm{~min}$ to prepare the next injection. Fluorescence excitation and emission wavelengths were set at 213 and $308 \mathrm{~nm}$, respectively. The linearity was $\mathrm{R}^{2}=0.997$ within the range $0.25-10 \mathrm{mg} / \mathrm{L}, \mathrm{LOQ}=0.18 \mathrm{mg} / \mathrm{L}$ and the recovery rate was between 89 and $98 \%$. The precision (repeatability and reproducibility) never exceeded $11 \%$ variability. Calibration solutions were prepared in synthetic wine $(6 \mathrm{~g} / \mathrm{L}$ of tartaric acid, $18 \%(\mathrm{v} / \mathrm{v})$ ethanol and $\mathrm{pH} 3.50)$.

The analysis of Arg and Cit was based on a previously described method [28] with slight changes, using an in-loop IDA/OPA/MCE derivatization followed by RP-HPLCFLD. Briefly, before derivatization, $100 \mu \mathrm{L}$ of each sample was diluted in $1 \mathrm{~mL}$ of $400 \mathrm{mM}$ borate buffer solution ( $\mathrm{pH}$ 10.5). The total derivatization reaction volume (strictly added in the following order: $5 \mu \mathrm{L}$ of buffered sample, $5 \mu \mathrm{L}$ of IDA solution and $10 \mu \mathrm{L}$ of OPA/MCE solution) was kept in the loop for 2 min before loading into an XBridge C18 RP column, $150 \times 2.1 \mathrm{~mm}, 3.5 \mu \mathrm{m}$, from Waters (Milford, MA, USA), thermostated at $45{ }^{\circ} \mathrm{C}$. The gradient elution was set at $0.3 \mathrm{~mL} / \mathrm{min}$, using solution A ( $1 \%$ tetrahydrofuran, $8 \%$ methanol and 91\% $10 \mathrm{mM}$ phosphate buffer ( $\mathrm{pH}$ 8.0)) and solution $\mathrm{B}$ (methanol) as follows: solution A was initially kept at $100 \%$ for $14 \mathrm{~min}$, changed to $50 \%$ for another $14 \mathrm{~min}$, decreased to $10 \%$ for the next $12 \mathrm{~min}$ and, finally, increased to $100 \%$ for $3 \mathrm{~min}$ to prepare the next injection. Fluorescence excitation and emission wavelengths were set at 335 and $440 \mathrm{~nm}$, respectively. Seven calibration points were prepared between 1 and $300 \mathrm{mg} / \mathrm{L}$, diluting a stock solution containing both amino acids at $300 \mathrm{mg} / \mathrm{L}$. A linearity of $\mathrm{R}^{2}=0.999$ was obtained for Arg, with a recovery rate between 86 and $99 \%$ and the repeatability and reproducibility never exceeding $13 \%$ RSD. For Cit, a linearity of $R^{2}=0.998$, an inter-day and intra-day precision of $<8 \%$ RSD and a recovery rate ranging between 86 and $97 \%$ were obtained. LOQs were 0.83 and $0.46 \mathrm{mg} / \mathrm{L}$ for Arg and Cit, respectively. Samples with Arg concentrations between 300 and $600 \mathrm{mg} / \mathrm{L}$ were diluted to 1/2, between 600 and $900 \mathrm{mg} / \mathrm{L}$ to $1 / 3$ and above $900 \mathrm{mg} / \mathrm{L}$ were diluted to $1 / 4$ before being dissolved in borate buffer.

Significant differences were evaluated by analysis of variance (one-way ANOVA with Holm-Sidak method) using the statistical software SigmaPlot v.12.0. All results were presented as mean \pm standard deviation (SD) of duplicate determinations of the sample duplicates $(n=8)$. The level of statistical significance was set at $p<0.05(95 \%$ confidence interval).

\section{Results and Discussion}

\subsection{Development of Ethyl Carbamate Precursors}

The urea concentration found in sweet and dry wines sampled before alcoholic fortification was strongly dependent on the non-Saccharomyces yeast strain inoculated (Figure 1A). In the sweeter wines, the urea content varied from $1.26 \pm 0.08$ to $5.3 \pm 0.6 \mathrm{mg} / \mathrm{L}$, with $H$. uvarum and P. terricola being responsible for the lower levels of about $1.3 \mathrm{mg} / \mathrm{L}$. P. fermentans and P. kluyveri ferments yielded the highest contents of $4.3 \pm 0.2$ and $5.3 \pm 0.6 \mathrm{mg} / \mathrm{L}$, respectively. This can be justified by the assumption that these yeasts have a higher affinity to convert Arg into urea, as previously pointed out [11]. These results suggest that the use of these two non-Saccharomyces strains as yeast starters can lead to high levels of urea and, therefore, a greater potential to develop EC. In the drier wines, the urea concentration ranged from $1.9 \pm 0.6$ to $2.5 \pm 0.2 \mathrm{mg} / \mathrm{L}$. P. terricola inoculation led to the lowest levels, while $S$. bacillaris resulted in the highest. The sweet wines under study presented lower urea contents than those fermented by Saccharomyces yeasts found in the literature, while dry wines had values of the same concentration level [29,30]. 

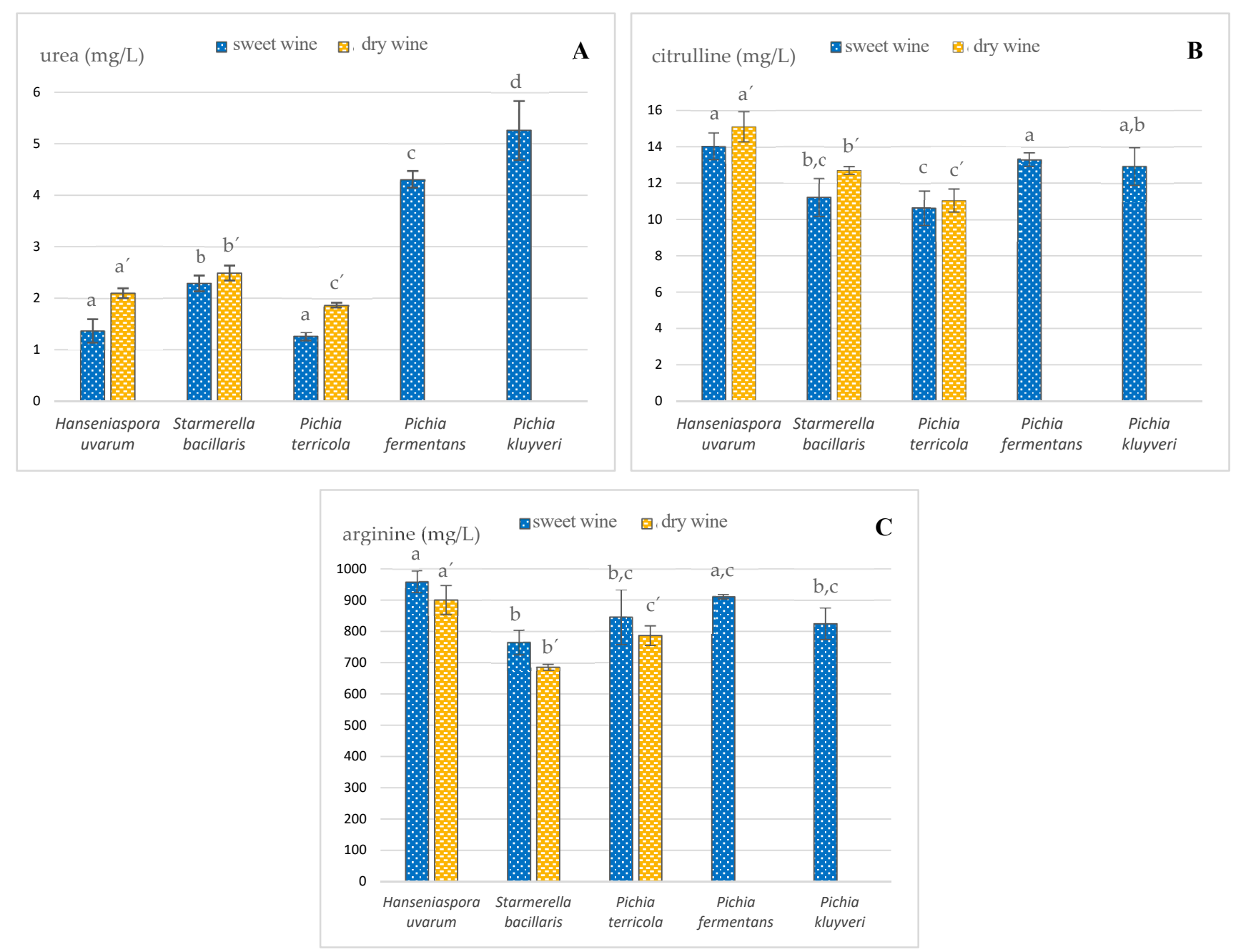

Figure 1. Impact of different indigenous non-Saccharomyces yeasts on the levels of (A) urea, (B) citrulline and (C) arginine found in sweet and dry wines sampled before alcoholic fortification; different letters within the same type of wine denote statistically significant differences $(p<0.05)$ according to Holm-Sidak test. Data represent the average taken from duplicate experiments.

Another relevant EC precursor in wines is Cit. In fermentation processes driven by Saccharomyces cerevisiae, Cit is generated through Arg anabolism, during which ornithine and carbamoyl phosphate react to form Arg, with Cit being an intermediate product of this metabolism [10]. Thus, it was expected that the activity of this metabolism might differ according to the yeast strain. High levels of Cit in wines are usually associated with the occurrence of malolactic fermentation [31,32]. Although malolactic fermentation is not usually induced in the vinification of Madeira, this kind of fermentation can occur spontaneously due to the bacteria naturally present and increase the content of Cit, which, in turn, can contribute to EC development during wine aging. However, this possibility was discarded in the present study due to must boiling. Figure 1B depicts the results of this EC precursor in the current sample set, and it can be confirmed that different strains of non-Saccharomyces yeasts generated different levels of Cit in the extracellular medium, with values ranging from $10.6 \pm 1.3$ to $15.1 \pm 0.8 \mathrm{mg} / \mathrm{L}$. S. bacillaris and P. terricola originated the lowest Cit contents in the sampled sweet wines at $11.2 \pm 1.1$ and $10.6 \pm 1.0 \mathrm{mg} / \mathrm{L}$, respectively. In the dry wine style, $P$. terricola showed, once again, the lowest level of Cit $(11.0 \pm 0.6 \mathrm{mg} / \mathrm{L})$, while the highest was obtained from the H. uvarum inoculation $(15.1 \pm 0.8 \mathrm{mg} / \mathrm{L})$. The observed values of Cit are comparable or lower than those observed in previous reports $[9,33]$. 
In a parallel study (under publication process), it was found that Arg can chemically react with ethanol to form EC under accelerated aging conditions, although it was much less reactive than urea and $\mathrm{Cit}$. Figure $1 \mathrm{C}$ shows that the different indigenous non-Saccharomyces yeasts inoculated in this study also influenced the levels of Arg in both styles of wines, varying from $687 \pm 9$ to $959 \pm 35 \mathrm{mg} / \mathrm{L}$. All wines fermented by H. uvarum and P. fermentans presented higher contents of Arg (930 and $816 \mathrm{mg} / \mathrm{L}$, respectively), while those fermented by $S$. bacillaris presented the lowest $(726 \mathrm{mg} / \mathrm{L})$. It is worth mentioning that the dry wine style did not reveal substantial differences in relation to the corresponding sweet wines. The fact that different yeasts have different affinities for Arg as a nitrogen source can justify these results.

The results obtained for sweet wines are comparable to those of wines in the beginning of the fermentation process with Saccharomyces yeasts [29,34], while those of the dry style are not. It is recognized that Arg is a good source of nitrogen for Saccharomyces yeasts, as its significant decrease is commonly observed, often more than $90 \%$. These results seem to indicate that the studied non-Saccharomyces yeasts have a lower affinity for Arg as a source of nitrogen, which is consistent with the low levels of urea detected in the sweet wines (Figure 1A), when compared to similar studies previously reported for Saccharomyces or native yeasts $[29,34-36]$.

\subsection{Ethyl Carbamate Formation Potential with Wine Aging}

As mentioned earlier, the resulting wines were fortified and exposed to laboratoryaccelerated aging at $70{ }^{\circ} \mathrm{C}$ for 1 month to evaluate the potential of the wines of each yeast strain to form EC during aging. Figure 2 shows that the EC content varied from $78.7 \pm 0.4 \mu \mathrm{g} / \mathrm{L}$ in wines inoculated with $P$. terricola to $178 \pm 27 \mu \mathrm{g} / \mathrm{L}$ in wines inoculated with P. kluyveri. P. terricola produced lower amounts of urea and Cit, and the resultant wines were those that showed less potential to form EC. Similarly, the wines derived from S. bacillaris, which is one of the most promising species for winemaking [37], presented low concentrations of EC precursors, showing EC concentrations of less than $100 \mu \mathrm{g} / \mathrm{L}$.

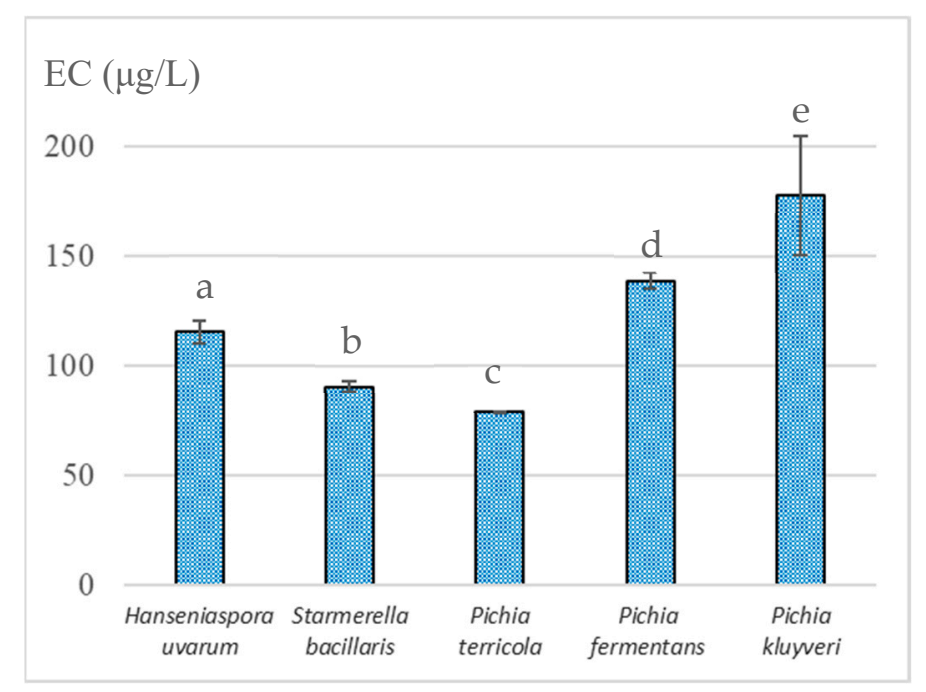

Figure 2. Ethyl carbamate concentration in fortified wines exposed to accelerated aging at $70{ }^{\circ} \mathrm{C}$ for 1 month and previously fermented with different indigenous non-Saccharomyces yeasts isolated from Madeira Island vineyards; different letters denote statistically significant differences $(p<0.05)$ according to Holm-Sidak test. Data represent the average taken from duplicate experiments.

\section{Conclusions}

This study showed that P. terricola and S. bacillaris are non-Saccharomyces yeasts that generate lower concentrations of the most reactive EC precursors, which can produce safer wines with different degrees of sweetness. The urea concentration in the extracellular 
medium was less than $1.9 \mathrm{mg} / \mathrm{L}$, while the Cit concentration was lower than $11.2 \mathrm{mg} / \mathrm{L}$. The inoculations performed individually using both yeasts generated average Arg levels of $771 \mathrm{mg} / \mathrm{L}$. It was also concluded that these non-Saccharomyces yeasts produced sweet wines with lower levels of urea and drier wines with higher levels of Arg, probably due to a lower affinity for Arg as a source of nitrogen when compared to the Saccharomyces yeasts reported in the literature. The resultant wines, which were fortified and exposed to accelerated aging, also revealed low levels of EC, below $100 \mu \mathrm{g} / \mathrm{L}$. Thus, S. bacillaris and P. terricola showed low potential to form EC in wines. Thus, these results provide relevant information for the utilization of these yeasts for EC mitigation purposes in wines. Moreover, these strains can eventually participate in the elaboration of more differentiated fortified wines, reflecting the characteristic of a given wine region, particularly in terms of organoleptic properties. The requirement for full fermentation dryness is not necessary in these fortified wines; as such, co-inoculation with Saccharomyces starters may be avoided. Therefore, the next studies will evaluate in detail their fermentation performances, the utilization of nitrogen sources and the volatile compound production to find a good compromise between wine quality and safety.

Supplementary Materials: The following are available online at https:/ /www.mdpi.com/article/10 .3390/pr9050799/s1.

Author Contributions: Conceptualization, J.M.L. and V.P.; validation, J.M.L., V.P. and J.C.M.; formal analysis, J.M.L.; investigation, J.M.L. (chemical analysis), A.M. and M.M.-F. (microbiology); resources, J.C.M.; writing—original draft preparation, J.M.L. and A.M.; writing—review and editing, V.P. and M.M.-F.; visualization, J.M.L.; supervision, V.P., J.C.M. and J.L.V.; project administration, V.P. and J.C.M.; funding acquisition, V.P. and J.C.M. All authors have read and agreed to the published version of the manuscript.

Funding: João M. Leça (PhD studentship), Andreia Miranda (PhD studentship) and Vanda Pereira (Post-Doc fellowship) were financially supported by ARDITI (Agência Regional para o Desenvolvimento da Investigação Tecnologia e Inovação), grant number M1420-09-5369-FSE-000001. This work was developed within the scope of the projects i3N and AROMA, funded by FEDER, through CENTRO2020-Programa Operacional Regional do Centro, CENTRO-01-0145-FEDER-031568, and by national funds (OE), PTDC/EEI-EEE/31568/2017, UIDB/50025/2020 and UIDP/50025/2020, through FCT/MCTES.

Institutional Review Board Statement: Not applicable.

Informed Consent Statement: Not applicable.

Data Availability Statement: The data presented in this study are available in supplementary material.

Acknowledgments: Andreia Miranda is thankful to Rita Tentem for providing the facilities of Laboratório Regional de Veterinária e Segurança Alimentar (Funchal, Madeira Island) for developing the microbiology studies under her supervision and the guidance of Manuel Malfeito-Ferreira from Instituto Superior de Agronomia (Lisbon University). The authors are also thankful to Madeira Wine Company for kindly providing the grapes used in this study.

Conflicts of Interest: The authors declare no conflict of interest. The funders had no role in the design of the study; in the collection, analyses, or interpretation of data; in the writing of the manuscript, or in the decision to publish the results.

\section{References}

1. Comitini, F.; Capece, A.; Ciani, M.; Romano, P. New insights on the use of wine yeasts. Curr. Opin. Food Sci. 2017, 13, 44-49. [CrossRef]

2. Capozzi, V.; Di Toro, M.R.; Grieco, F.; Michelotti, V.; Salma, M.; Lamontanara, A.; Russo, P.; Orrù, L.; Alexandre, H.; Spano, G. Viable but Not Culturable (VBNC) state of Brettanomyces bruxellensis in wine: New insights on molecular basis of VBNC behaviour using a transcriptomic approach. Food Microbiol. 2016, 59, 196-204. [CrossRef]

3. Zarraonaindia, I.; Owens, S.M.; Weisenhorn, P.; West, K.; Hampton-Marcell, J.; Lax, S.; Bokulich, N.A.; Mills, D.A.; Martin, G.; Taghavi, S.; et al. The Soil Microbiome Influences Grapevine-Associated Microbiota. mBio 2015, 6, 14-23. [CrossRef]

4. Padilla, B.; Gil, J.V.; Manzanares, P. Past and Future of Non-Saccharomyces Yeasts: From Spoilage Microorganisms to Biotechnological Tools for Improving Wine Aroma Complexity. Front. Microbiol. 2016, 7, 7-20. [CrossRef] 
5. IARC. Alcohol Consumption and Ethyl Carbamate; IARC Press, International Agency for Research on Cancer: Lyons, France, 2010; Volume 96.

6. Conacher, H.; Page, B. Ethyl carbamate in alcoholic beverages: A canadian case history. In Proceedings of Euro Food Tox II; European Society of Toxicology: Schwerzenbach, Switzerland, 1986; pp. 237-242.

7. Government of Canada. Health Canada's Maximum Levels for Chemical Contaminants in Foods. Available online: https: //www.canada.ca/en/health-canada/corporate/contact-us.html (accessed on 17 March 2021).

8. Jiao, Z.; Dong, Y.; Chen, Q. Ethyl Carbamate in Fermented Beverages: Presence, Analytical Chemistry, Formation Mechanism, and Mitigation Proposals. Compr. Rev. Food Sci. Food Saf. 2014, 13, 611-626. [CrossRef] [PubMed]

9. Davis, R.H. Compartmental and regulatory mechanisms in the arginine pathways of Neurospora crassa and Saccharomyces cerevisiae. Microbiol. Rev. 1986, 50, 280-313. [CrossRef] [PubMed]

10. Butzke, C.E.; Bisson, L.F. Ethyl Carbamate Preventative Action Manual; US Food and Drug Administration, Center for food safety and Applied nutrition: Washington, DC, USA, 1997.

11. Azevedo, Z.; Couto, J.A.; Hogg, T. Citrulline as the main precursor of ethyl carbamate in model fortified wines inoculated with Lactobacillus hilgardii: A marker of the levels in a spoiled fortified wine. Lett. Appl. Microbiol. 2002, 34, 32-36. [CrossRef]

12. Kodama, S.; Suzuki, T.; Fujinawa, S.; Teja, P.; Yotsuzuka, F. Urea Contribution to Ethyl Carbamate Formation in Commercial Wines During Storage. Am. J. Enol. Vitic. 1994, 45, 17-24.

13. Stevens, D.F.; Ough, C.S. Ethyl Carbamate Formation: Reaction of Urea and Citrulline with Ethanol in Wine Under Low to Normal Temperature Conditions. Am. J. Enol. Vitic. 1993, 44, 309-312.

14. An, D.; Ough, C.S. Urea Excretion and Uptake by Wine Yeasts as Affected by Various Factors. Am. J. Enol. Vitic. 1993, 44, 35-40.

15. Henschke, P.A.; Ough, C.S. Urea Accumulation in Fermenting Grape Juice. Am. J. Enol. Vitic. 1991, 42, 317-321.

16. Coulon, J.; Husnik, J.I.; Inglis, D.L.; van der Merwe, G.K.; Lonvaud, A.; Erasmus, D.J.; van Vuuren, H.J.J. Metabolic Engineering of Saccharomyces cerevisiae to Minimize the Production of Ethyl Carbamate in Wine. Am. J. Enol. Vitic. 2006, 57, 113.

17. Pereira, V.; Pereira, A.C.; Marques, J.C. 13-Emerging Trends in Fortified Wines: A Scientific Perspective. In Alcoholic Beverages; Grumezescu, A.M., Holban, A.M., Eds.; Woodhead Publishing: Amsterdam, The Netherlands, 2019; pp. 419-470.

18. Perestrelo, R.; Silva, C.; Pereira, J.; Câmara, J.S. Wines: Madeira, Port and Sherry Fortified Wines-The Sui Generis and Notable Peculiarities. Major Differences and Chemical Patterns. In Encyclopedia of Food and Health; Caballero, B., Finglas, P.M., Toldrá, F., Eds.; Academic Press: Oxford, UK, 2016; pp. 534-555.

19. Elliott, T. Viticulture. In The Wines of Madeira: An Indispensable Guide to the Wines, Grapes and Producers, 1st ed.; Trevor Elliott Publishing: Hampshire, UK, 2010.

20. Jackson, R.S. Chemical Constituents of Grapes and Wine. Wine Science, 2nd ed.; Academic Press: San Diego, CA, USA, 2000.

21. Esteve-Zarzoso, B.; Belloch, C.; Uruburu, F.; Querol, A. Identification of yeasts by RFLP analysis of the 5.8S rRNA gene and the two ribosomal internal transcribed spacers. Int. J. Syst. Evol. Microbiol. 1999, 49, 329-337. [CrossRef]

22. Benito, S.; Calderón, F.; Benito, Á. The Combined Use of Schizosaccharomyces pombe and Lachancea thermotolerans-Effect on the Anthocyanin Wine Composition. Molecules 2017, 22, 739. [CrossRef] [PubMed]

23. OIV. Alcoholic Strength by Volume, OIV-MA-AS312-01B, Compendium of International Methods of Analysis. 2009. Resolution Oeno 377/2009. Available online: https:/ / www.oiv.int/public/medias/2490/oiv-ma-as312-01b.pdf (accessed on 28 April 2021).

24. Pereira, V.; Cacho, J.; Marques, J.C. Volatile profile of Madeira wines submitted to traditional accelerated ageing. Food Chem. 2014, 162, 122-134. [CrossRef] [PubMed]

25. Pereira, V.; Santos, M.; Cacho, J.; Marques, J.C. Assessment of the development of browning, antioxidant activity and volatile organic compounds in thermally processed sugar model wines. LWT Food Sci. Technol. 2017, 75, 719-726. [CrossRef]

26. Leça, J.M.; Pereira, V.; Pereira, A.C.; Marques, J.C. A Sensitive Method for the Rapid Determination of Underivatized Ethyl Carbamate in Fortified Wine by Liquid Chromatography-Electrospray Tandem Mass Spectrometry. Food Anal. Methods 2017, 11, 327-333. [CrossRef]

27. Zhang, J.; Liu, G.; Zhang, Y.; Gao, Q.; Wang, D.; Liu, H. Simultaneous Determination of Ethyl Carbamate and Urea in Alcoholic Beverages by High-Performance Liquid Chromatography Coupled with Fluorescence Detection. J. Agric. Food Chem. 2014, 62, 2797-2802. [CrossRef] [PubMed]

28. Pereira, V.; Pontes, M.; Câmara, J.S.; Marques, J.C. Simultaneous analysis of free amino acids and biogenic amines in honey and wine samples using in loop orthophthalaldeyde derivatization procedure. J. Chromatogr. A 2008, 1189, 435-443. [CrossRef] [PubMed]

29. Boeira, L.S.; Pereira, C.N.; Daudt, C.E. Arginine and urea evolution during musts fermentation of cv gewürztraminer from different nitrogen fertilizer levels in the soil. Ciência Rural 1995, 25, 295-298. [CrossRef]

30. Monteiro, F.F.; Bisson, L.F. Amino Acid Utilization and Urea Formation During Vinification Fermentations. Am. J. Enol. Vitic. 1991, 42, 199.

31. Arena, M.E.; Saguir, F.M.; Manca de Nadra, M.C. Arginine, citrulline and ornithine metabolism by lactic acid bacteria from wine. Int. J. Food Microbiol. 1999, 52, 155-161. [CrossRef]

32. Mira de Orduña, R.; Liu, S.-Q.; Patchett, M.L.; Pilone, G.J. Ethyl carbamate precursor citrulline formation from arginine degradation by malolactic wine lactic acid bacteria. FEMS Microbiol. Lett. 2000, 183, 31-35. [CrossRef]

33. Terrade, N.; Mira de Orduña, R. Impact of winemaking practices on arginine and citrulline metabolism during and after malolactic fermentation. J. Appl. Microbiol. 2006, 101, 406-411. [CrossRef] [PubMed] 
34. Pereira, V.; Pereira, A.C.; Trujillo, J.P.P.; Cacho, J.; Marques, J.C. Amino Acids and Biogenic Amines Evolution during the Estufagem of Fortified Wines. J. Chem. 2015, 2015, 1-9. [CrossRef]

35. Bisson, L.F. Influence of nitrogen on yeast and fermentation of grapes. In Proceedings of the International Symposium on Nitrogen in Grapes and Wine Seattle, Washington, DC, USA, 18-19 June 1991; pp. 78-89.

36. Valero, E.; Millán, C.; Ortega, J.M.; Mauricio, J.C. Concentration of amino acids in wine after the end of fermentation by Saccharomyces cerevisiae strains. J. Sci. Food Agric. 2003, 83, 830-835. [CrossRef]

37. Englezos, V.; Giacosa, S.; Rantsiou, K.; Rolle, L.; Cocolin, L. Starmerella bacillaris in winemaking: Opportunities and risks. Curr. Opin. Food Sci. 2017, 17, 30-35. [CrossRef] 